\title{
COLETOR SOLAR PARA PRÉ-AQUECIMENTO DO AR EM SISTEMAS DE SECAGEM ESTUDO DE CASO - CURA DO TABACO
}

\author{
Martha Lisa Rodrigo Schuck ${ }^{1}$ \\ Joaquim Pizzutti dos Santos ${ }^{2}$ \\ Roberta Mulazzani Doleys Soares ${ }^{3}$ \\ Giana da Rocha Zófoli ${ }^{4}$ \\ Liége Garlet ${ }^{5}$ \\ Giane de Campos Grigoletti ${ }^{6}$
}

\section{Resumo}

Este trabalho apresenta o projeto, a construção e a avaliação da eficiência de um coletor solar plano para pré-aquecimento do ar, executado com materiais de baixo custo, a ser utilizado em sistemas de secagem. O protótipo do coletor solar foi construído em uma propriedade de Santa Cruz do Sul-RS, para o levantamento de dados de temperatura e umidade relativa do ar, utilizando-se aparelhos registradores, e efetuando-se os cálculos de determinação do calor útil fornecido. Como estudo de caso foi proposta a utilização deste coletor solar como sistema suplementar para aquecimento do ar no processo de cura do tabaco nas estufas existentes. Um processo de cura foi acompanhado para verificação do consumo de lenha necessário, para possível determinação da demanda energética. Observou-se que a utilização do coletor com $3 \mathrm{~m}^{2}$ de área proporcionou a redução de $5,2 \%$ no consumo de lenha, o que demonstrou viabilidade econômica da utilização do sistema com tempo de retorno do investimento de 3,4 anos.

\footnotetext{
${ }^{1}$ Programa de Pós-Graduação em Engenharia Civil e Ambiental. E-mail: marthalisarodrigo@yahoo.com.br

${ }^{2}$ Programa de Pós-Graduação em Engenharia Civil e Ambiental. E-mail: joaquim@smail.ufsm.br

${ }^{3}$ Professora no Curso de Arquitetura e Urbanismo (URI Campus Santo Ângelo). E-mail: roberta.doleys@gmail.com

${ }^{4}$ Professora no Curso de Arquitetura e Urbanismo (URI Campus Santiago). E-mail: gianazofoli@yahoo.com.br

${ }^{5}$ Graduanda no Curso de Arquitetura e Urbanismo (CAU-UFSM). E-mail: liegeg9@gmail.com

${ }^{6}$ Programa de Pós-Graduação em Engenharia Civil e Ambiental. E-mail: ggrigoletti@gmail.com
} 
Palavras-chave: estufa à lenha; protótipo; sistema de secagem.

\title{
SOLAR COLLECTOR FOR AIR PRE-HEATING ON DRYING SYSTEMS \\ CASE STUDY - CURING TOBACCO
}

\begin{abstract}
This paper presents the design, construction and evaluation of the efficiency of a flat solar collector for pre-heating the air, executed with low cost materials, to be used in drying systems. The prototype of the solar collector was built on an city of Santa Cruz do Sul - RS, to the data collection temperature and relative humidity, using registers, and performing the calculations for determining the useful heat supplied. As a case study, proposed to use this as supplemental solar collector system for heating the air in the curing of tobacco in existing greenhouses process. It was observed that the application of a 3sqm surface collector represented a reduction of around $5.2 \%$ in firewood consumption, which demonstrated the economic viability of the system with a time of payback of 3.4 years.
\end{abstract}

Key words: wood-fired oven, prototype; drying system.

\section{INTRODUÇÃO}

A energia solar pode ser utilizada para diversas finalidades, substituindo, em muitos casos, com vantagens, outras formas convencionais de energia que vêm sendo utilizadas pelo homem há décadas. É uma forma absolutamente pura, não poluente, não produz fumaça e nem resíduos radioativos. Constitui-se, portanto, uma forma ideal de energia tendo em vista a proteção ao meio ambiente.

Produtores rurais enfrentam um grande problema para a secagem de grãos, segundo GUANDAGNIN (2005), a maior parte dos produtores utiliza a secagem de grãos com energia produzida pela queima de lenha. Porém, esse método prejudica a qualidade do grão devido à alta temperatura de secagem, além de ser um processo muito caro.

GRATTO et. al (2003), reforça que, no Brasil, a fonte de energia mais utilizada para a cura do tabaco tem sido a lenha, que 
para o momento, dado os tipos de estufas utilizadas, tem-se apresentado economicamente como a melhor alternativa. No Rio Grande do Sul existem aproximadamente 85.560 propriedades produtoras de tabaco, que totalizam cerca de 91.420 estufas de cura. A lenha é o terceiro energético primário consumido no Brasil, com um valor médio, nos últimos 26 anos, de 9,78 x 107 toneladas/ano.

Este trabalho visa projetar, construir e avaliar a eficiência de um coletor solar plano para pré-aquecimento do ar, com materiais de baixo custo, a ser utilizado em sistemas de secagem. Como estudo de caso, foi proposta a utilização deste coletor solar como sistema de pré-aquecimento do ar para a cura do tabaco em estufas à lenha, existentes, suplementando o calor necessário no processo. protótipo foi construído em uma propriedade de Santa Cruz do Sul.

Como principais vantagens do emprego de energia solar com esta finalidade, pode-se citar:

- Uso de fonte limpa de energia, ao contrário da lenha, que durante o processo de combustão, libera $\mathrm{CO}_{2}$;

- Vantagem econômica, especialmente em pequenas propriedades, uma vez que, depois de instalado, o custo do seu funcionamento é pequeno e diminuirá o emprego da lenha.

\section{MATERIAIS E MÉTODOS}

\subsection{Coletor solar a ar com leito de britas}

Para este estudo foi desenvolvido um coletor solar a ar, construindo um protótipo em uma propriedade de Santa Cruz do Sul - RS, considerando alguns fatores essenciais, como a adaptabilidade construtiva, 0 baixo custo dos materiais e a praticidade de instalação.

Para o desenvolvimento do coletor solar a ar foi utilizada a metodologia descrita por SANTOS (2004): coletor com sua face voltada para o norte e sua superfície com um ângulo de inclinação igual à latitude do local, visando otimizar a incidência de radiação solar. O leito armazenador abriga uma camada de pedras britadas $\mathrm{n}^{\circ} 1$, possuindo espessura de $20 \mathrm{~cm}$ e uma área coletora é de $3,60 \mathrm{~m}^{2}$ $(h=1,19$ e $L=3,04)$. A cobertura é de vidro incolor, $5 \mathrm{~mm}$, e o espaço entre o leito armazenador e a cobertura de vidro é de $5 \mathrm{~cm}$ (Figuras 1 e 2). 


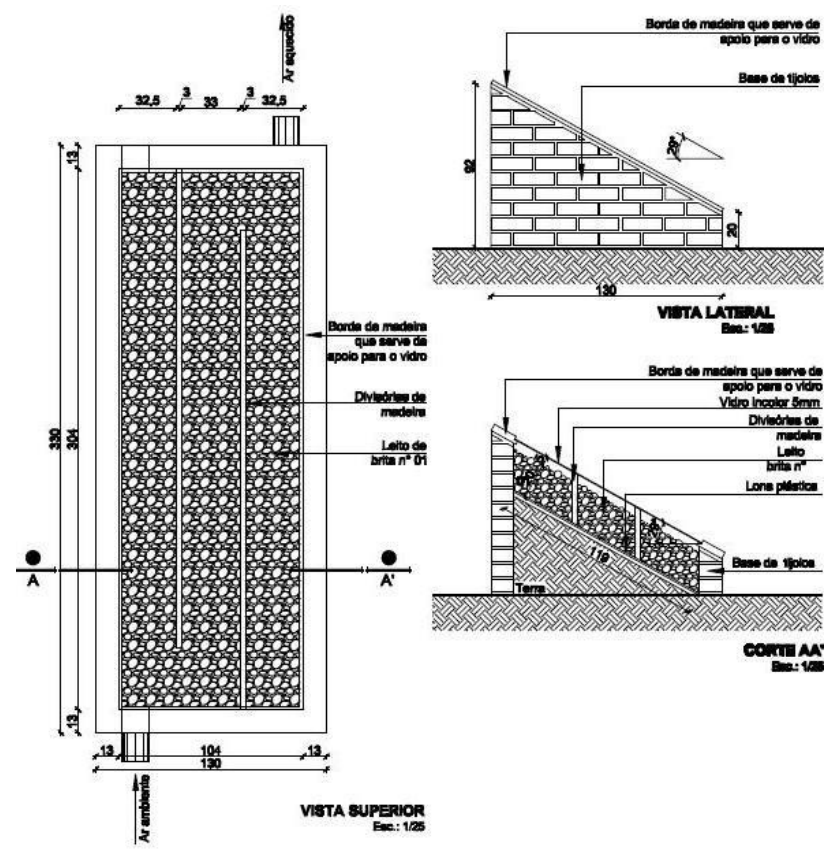

Figura 1 - Detalhamento do projeto do coletor solar a ar.

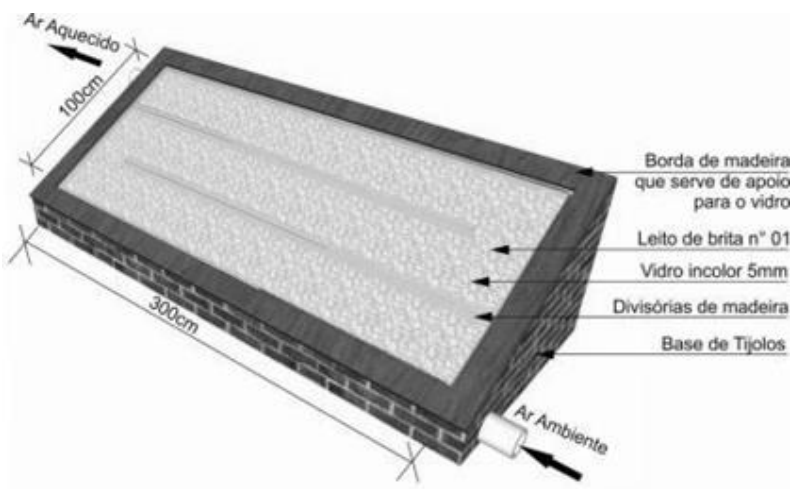

Figura 2 - Perspectiva ilustrativa do coletor solar a ar.

A base em tijolos foi executada para que o leito armazenador e a cobertura de vidro ficassem com o ângulo de 
inclinação adequado, sendo colocada uma lona plástica para evitar o fluxo de água do solo para o leito (Figura 3). Em seguida foram colocadas as divisórias de madeira definindo a trajetória do ar (visando aumentar o tempo de permanência e a turbulência do fluxo de ar) e a camada de $20 \mathrm{~cm}$ de pedras britadas $n^{\circ} 1$ que forma o leito armazenador de energia, a Figura 4 apresenta 0 coletor solar concluído.

Para a colocação da cobertura de vidro transparente foi executado um quadro de madeira, fixo com argamassa de cimento e vedação silicone.

$\mathrm{Na}$ entrada de ar, instalou-se um ventilador da Marca Ventokit modelo Ventokit 280, que apresenta uma vazão de $280 \mathrm{~m}^{3} / \mathrm{h}$.

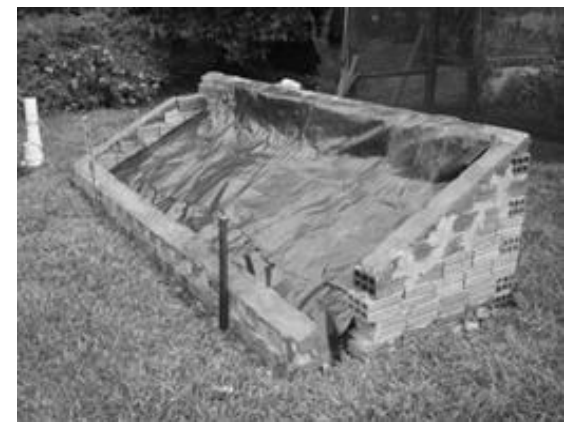

Figura 3 - Construção do coletor.

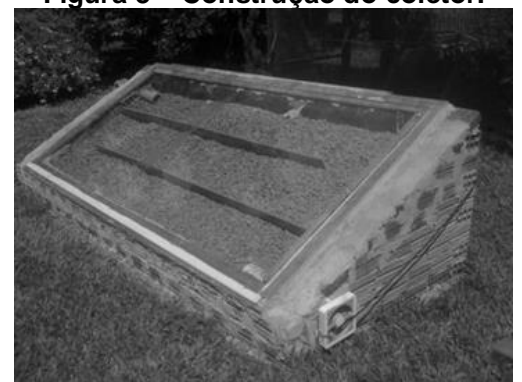

Figura 4 - Vista do Coletor solar pronto.

\subsection{Avaliação do protótipo do coletor solar a ar com leito de britas}

Para a avaliação do coletor solar de energia, utilizou-se uma série de equipamentos e equações que serão descritos a seguir. 


\subsubsection{Equipamentos de medições}

a) Medições de temperatura e umidade

Para o levantamento dos dados de temperatura e umidade foram utilizados aparelhos registradores de temperatura e umidade relativa do ar do tipo HOBO. E, para as medições externas, caixas de isopor revestidas internamente por papel alumínio e com aberturas para a entrada de ar, para proteção da radiação incidente sobre os aparelhos.

Este aparelho pode ser configurado para realizar leituras em intervalos de tempo determinados para um período pré-fixado, tendo a capacidade de armazenar 7.944 leituras, com intervalos de 0,5 segundos até 9 horas. No fim das medições os dados foram transmitidos para um computador por meio de um programa específico, o BoxCar 3.0.

Para a realização dos testes foram instalados cinco aparelhos do tipo HOBO para a coleta e armazenamento dos valores de temperaturas e umidade relativa nas extremidades do coletor, sendo utilizados dois aparelhos na entrada de ar do coletor (chamados nos resultados de E1-B1 e E1-B2) e três aparelhos na saída de ar do mesmo (S1-B1, S2-B2 e S3-B3), conforme a Figura 5 , sendo que dois destes ainda registravam as temperaturas através de cabos de leitura posicionados no interior do cano de PVC.

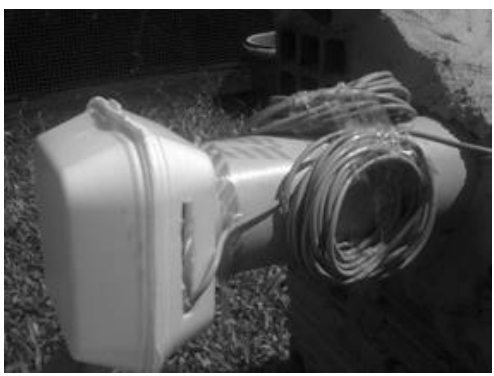

Figura 5 - Aparelhos de medição posicionados na saída de ar do coletor.

Os registradores foram programados para tomar leituras a cada cinco minutos dentro de um período de seis dias, que iniciou no dia 15/02/2012 e finalizou no dia 21/02/2012. 
b) Medições de Velocidade do ar

Para o levantamento da velocidade do ar utilizou-se um anemômetro digital da marca VelociCheck Modelo 8330 (TSI Incorported).

Como foi acoplado na entrada de ar do coletor, um ventilador que apresentava vazão contínua, as medições de velocidade do ar na saída do coletor, para o cálculo da vazão mássica, foram realizadas somente para conferência, apenas uma vez ao dia, não sendo observadas variações entre as leituras.

A velocidade do ar medida na saída do coletor foi de 4,9 $\mathrm{m} / \mathrm{s}$, conforme a vazão mássica de ar determinada de acordo com as equações abaixo:

$$
\begin{gathered}
m=V_{a r} A_{s e g} \rho_{a r} \\
\rho_{a r}=\frac{P_{a t m}}{287,09 T_{b s}} \\
A_{s e g}=\pi R^{2}
\end{gathered}
$$

Onde:

$m$ - vazão mássica de ar $(\mathrm{Kg} / \mathrm{s})$

$V_{a r}$ - velocidade do ar $(\mathrm{m} / \mathrm{s})$

$A_{s e c}$ - área da seção transversal do duto de alimentação do coletor $\left(\mathrm{m}^{2}\right)$

$\rho_{\text {ar }}$ - densidade do ar $\left(\mathrm{kg} / \mathrm{m}^{3}\right)$

$P_{a t m}$ - pressão atmosférica $(\mathrm{Pa})$

$T_{b s}$ - temperatura de bulbo seco do ar (K)

$R$ - raio da seção transversal do duto de alimentação do coletor (m)

Portanto, assumindo como densidade do ar $1,225 \mathrm{~kg} / \mathrm{m}^{3}$, (International Standard Atmosfere, 2012), ao nível do mar e a $15^{\circ} \mathrm{C}$, a vasão mássica de ar é de $169,63 \mathrm{~m}^{3} / \mathrm{h}=207,79 \mathrm{Kg} / \mathrm{h}\left(\mathrm{m}^{3}\right.$ de $\mathrm{ar}=$ $1,225-1,225 \times 155,78)$.

\subsubsection{Determinação do calor útil fornecido}

Para o cálculo da taxa de calor fornecida pelo coletor armazenador, é necessário o conhecimento da vazão mássica do ar e a variação de entalpia $\Delta H$ do ar no aquecimento. A variação de entalpia é dada pela diferença entre as entalpias do ar na entrada e na saída do coletor (Almeida, 2004), onde: 


$$
H=1,01 T+W(2463+1,88 T)
$$

Sendo:

$H$ - entalpia do ar ( $\mathrm{J} / \mathrm{kg}$ ar seco)

$T_{b s}$ - temperatura de bulbo seco do ar $\left({ }^{\circ} \mathrm{C}\right)$

$W$ - umidade absoluta $\left(\mathrm{kg} \mathrm{H}_{2} \mathrm{O} / \mathrm{kg}\right.$ ar seco)

Para o cálculo da umidade absoluta $W$ e demais propriedades psicrométricas do ar foram utilizadas equações apresentadas por Santos (2004). O valor da umidade absoluta é dado por:

$$
W=\frac{W_{s a} H_{i-v}+C_{p_{a r}}\left(T_{b u}-T_{b s}\right)}{\left(H_{v}-H_{i}\right)}
$$

Onde:

$W_{s a}$ - umidade absoluta de saturação adiabática

$H_{l-v}$ - entalpia da mudança de fase (líquido-vapor) $(\mathrm{kJ} / \mathrm{kg}$ )

$H_{V}$ - entalpia do vapor $(\mathrm{kJ} / \mathrm{kg})$

$H_{1}$ - entalpia do líquido $(\mathrm{kJ} / \mathrm{kg})$

$T_{b u}$ - temperatura de bulbo úmido do ar $\left({ }^{\circ} \mathrm{C}\right)$

$C_{p a r}$ - calor específico do ar $\left(1012 \mathrm{~J} / \mathrm{kg}^{\circ} \mathrm{C}\right.$ para temperaturas entre 0 e $\left.300^{\circ} \mathrm{C}\right)$

Os valores de entalpia envolvidos na equação 05 são obtidos pelas expressões:

$$
\begin{gathered}
H_{i-v}=2501-2,381 T_{b u} \\
H_{v}=2501+1,805 T_{b s} \\
H_{i}=4,186 T_{b u}
\end{gathered}
$$

A umidade absoluta de saturação adiabática é dada por:

Onde:

$$
W_{s a}=0,622 \frac{p_{v s a}}{p_{T}-p_{v s a}}
$$

$p_{v s a}$ - pressão de vapor de saturação adiabática $(\mathrm{Pa})$ $p_{T}$ - pressão total

A pressão de vapor de saturação adiabática pode ser calculada através da equação: 


$$
p_{v s a}=\exp \left[18,3036-\frac{3816,44}{T_{b u}(K)-46,13}\right](m m H G)
$$

Através das equações anteriores, determina-se a variação de entalpia do ar entre a entrada e a saída do coletor $(\Delta \mathrm{H})$. A taxa de calor útil fornecida pelo coletor é obtida pela equação 11 :

$$
Q_{u}=m \Delta H
$$

\subsection{Estudo de caso - Cura do tabaco}

A proposta deste estudo de caso considerou a utilização do coletor solar como sistema suplementar na cura do tabado em estufas existentes à lenha, com intuito de diminuir o consumo desta.

\subsubsection{Modelo de estufa considerado}

Uma estufa à lenha, típica, existente, foi utilizada como modelo para o estudo de implantação do sistema proposto, localizada na propriedade Bublitz, no interior do Município de Santa Cruz do Sul, a $17 \mathrm{~km}$ do centro da cidade na Linha Antão, estrada que liga Santa Cruz do Sul-RS à Monte Alverne, terceiro distrito da cidade.

A estufa possui $5 \mathrm{~m}$ de largura por $5 \mathrm{~m}$ de profundidade, um telhado de uma água com pé-direito de $6 \mathrm{~m}$ de altura no lado mais alto e de 5,5 no lado mais baixo. A fornalha está situada na fachada norte e no seu interior possui uma malha de 20 barrotes de madeira (04 na largura x 05 na altura) onde são amarrados os pés de tabaco. $\mathrm{Na}$ Figura 6 são apresentadas as perspectivas da estufa considerada. 


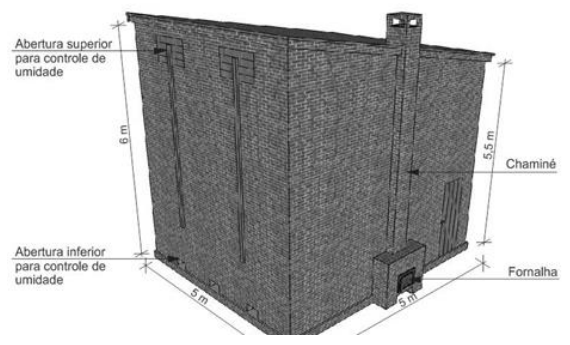

Figura 6 - Perspectivas ilustradas da estufa.

Dutos de aço galvanizado de $40 \mathrm{~cm}$ de diâmetro são utilizados para que a transferência de calor, proveniente da combustão da lenha

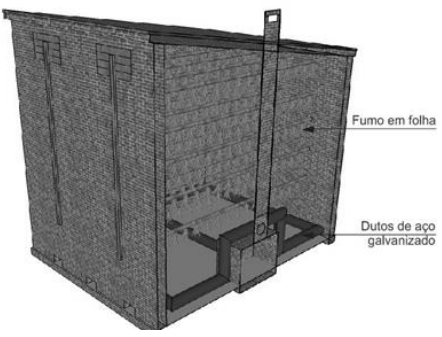
dentro da fornalha, ocorra por convecção natural devido à leve inclinação dos dutos até a chaminé. Assim que aquecidos, os dutos passam a irradiar o calor para dentro da estufa (Figura 7).

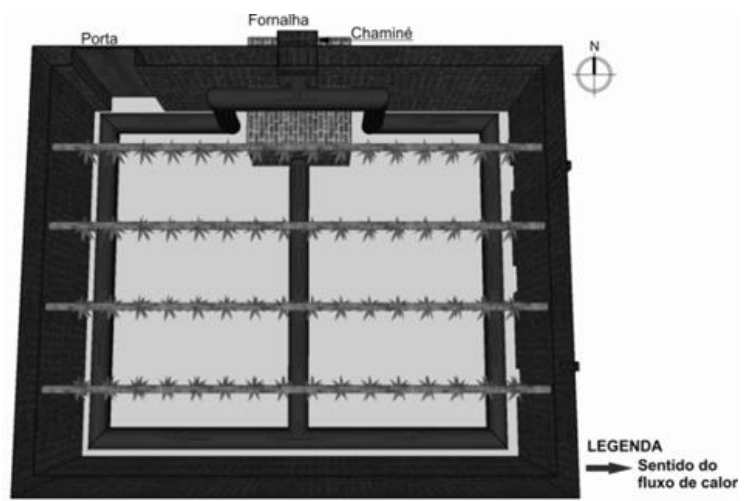

Figura 7 - Fluxo de calor nos dutos de aço galvanizado no interior da estufa.

\subsubsection{Estudo experimental da estufa}

A cura do tabaco é realizada dentro de uma estufa de características artesanais, na qual a variação da temperatura é decorrente da energia liberada pela combustão dentro de uma 
fornalha, em que a maior parte desta energia é transferida por convecção dentro da estufa. Alterando a temperatura juntamente com o fluxo de ar na estufa, pode-se estabelecer uma umidade relativa para cada fase do processo de cura.

Para a realização dos procedimentos experimentais de medição da temperatura, foram utilizados alguns componentes eletrônicos e instrumentos, bem como uma metodologia simples para a execução, que será descrita a seguir.

\subsubsection{Equipamentos}

Para o estudo experimental de medições no interior da estufa foram utilizados os seguintes equipamentos:

a) Sensor de Temperatura

Para a medição de temperatura, utilizou-se o sensor LM35, que é um sensor de precisão, fabricado pela National Semiconductor. Fornece uma escala de temperatura em graus Celsius, não necessitando de calibração externa para fornecer valores de temperatura com variações de $0,25^{\circ} \mathrm{C}$ dentro da faixa de temperatura de $-55^{\circ} \mathrm{C}$ à $150^{\circ} \mathrm{C}$.

b) Higrômetro tipo bulbo úmido e bulbo seco

A umidade é uma variável de grande importância para a cura do fumo. Com base nas informações de psicrometria serão utilizadas informações de temperatura, para o cálculo de umidade relativa, que pode ser determinada indiretamente através da medição de duas temperaturas: bulbo seco e bulbo úmido. Optou-se pelo uso do sensor LM35 devido a sua linearidade, na faixa de temperatura que ocorre no processo de cura $\left(10^{\circ} \mathrm{C}\right.$ a $\left.80^{\circ} \mathrm{C}\right)$, bem como por sua alta resistência a ambientes agressivos, como no caso de estufas de secagem de fumo.

A temperatura de bulbo seco é a obtida através do sensor que faz a leitura da temperatura do ambiente, e a temperatura de bulbo úmido é coletada através de um sensor coberto por um tecido de algodão, este tecido está imerso em um pote de água. Assim por capilaridade a água vai subindo até chegar ao sensor fazendo com que o bulbo deste fique recoberto de água.

Um protótipo de psicrômetro tipo bulbo úmido e bulbo seco, aspirado, foi construído. Neste protótipo, foi utilizado um ventilador da Marca Ventokit modelo Ventokit 280 (Figura 8), que apresenta 
uma vazão de $280 \mathrm{~m}^{3} / \mathrm{h}$, fornecendo assim uma velocidade média de $9,5 \mathrm{~m} / \mathrm{s}$ no interior do tubo de PVC que apresenta $100 \mathrm{~mm}$ de diâmetro.

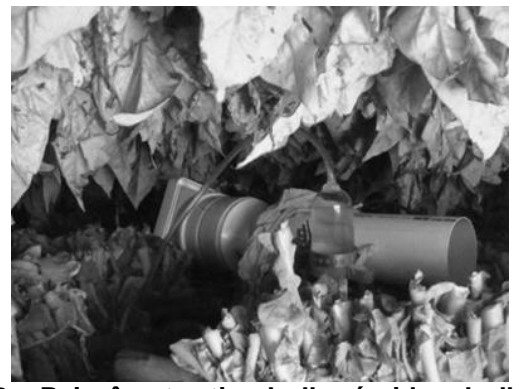

Figura 8 - Psicrômetro tipo bulbo úmido e bulbo seco.

Com isso, foi satisfeita a condição de que a velocidade deve ser de pelo menos $5 \mathrm{~m} / \mathrm{s}$ (ASHRAE, 2010).

Para o cálculo da umidade relativa, neste trabalho, foi considerado o ar úmido como um gás perfeito, sendo determinado utilizando a seguinte expressão:

$$
U R=\frac{e a}{e s} 100
$$

Onde:

$U R$ =umidade relativa

ea $=$ pressão de vapor real em $(\mathrm{kPa})$ que é calculada mediante a equação 13 , a seguir

es = pressão parcial de saturação na temperatura do ar $(\mathrm{kPa})$, calculada com a temperatura do bulbo seco.

$$
e_{a}=e_{s T u}-\left(\delta p\left(T_{b s}-t_{b u}\right)\right.
$$

Onde:

$\delta=$ constante psicrométrica sist. ventilado $\left(0,067 \mathrm{kPa} /{ }^{\circ} \mathrm{C}\right)$

$T_{b s}=$ temperatura do bulbo seco

$T_{b u}=$ temperatura do bulbo úmido

$e_{\text {sTu }}=$ pressão $(\mathrm{kPa})$ de vapor de saturação que foi calculada mediante a equação de Tetens utilizando a temperatura de bulbo úmido representada por: 


$$
e_{s}=0,611 * 10^{\left[\frac{7,5 T_{b s}}{237,3+T_{b s}}\right]}
$$

Finalmente, a umidade relativa é a razão calculada entre a pressão de vapor real e a pressão de vapor de saturação, expressa em porcentagem.

c) Placa de Aquisição e Sistema de Condicionamento do Sinal

Para gravar os dados no computador utilizou-se um datalogger da empresa Measurement Computing modelo USB1208FS.

2.3.2.2 Pontos de medição no interior da estufa

Os sensores de temperatura e o higrômetro de bulbo úmido e bulbo seco foram instalados no interior da estufa conforme o layout apresentado nas Figuras 9 e 10.

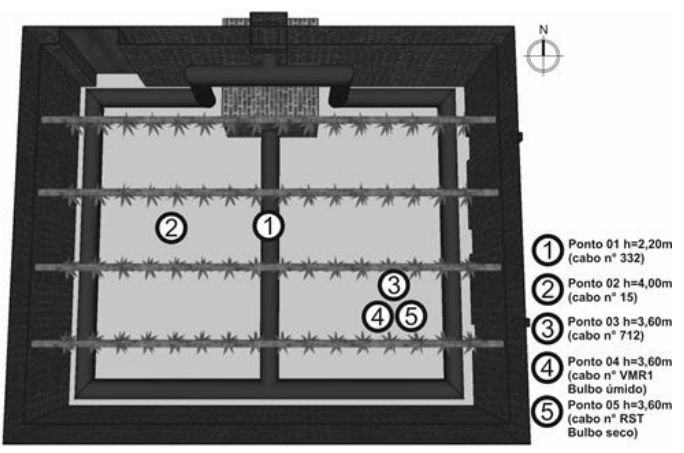

Figura 9 - Planta baixa da estufa com localização dos pontos de medições. 


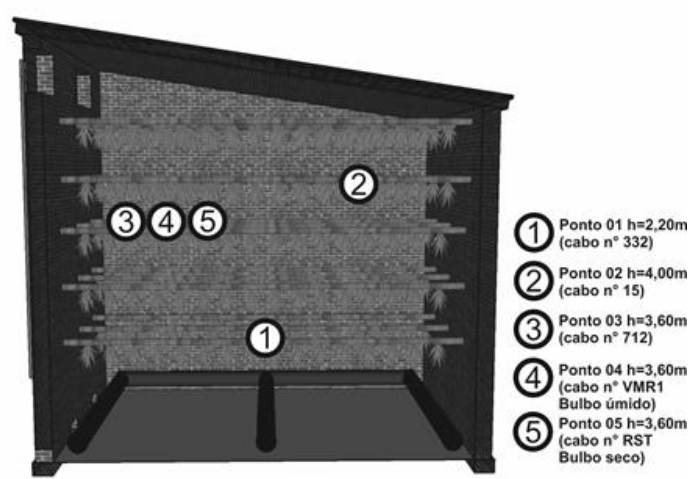

Figura 10- Corte da estufa com localização dos pontos de medições.

O sistema de aquisição dos dados iniciou o monitoramento no dia $19 / 01 / 2012$ e finalizou no dia $22 / 01 / 2012$, totalizando 42,7 horas de medição, no período que se refere à fase inicial do processo de cura do tabaco, a amarelação da folha.

Nos dias de medição a temperatura ambiente apresentou uma pequena variação de $3^{\circ} \mathrm{C}$, assim a faixa de temperatura ambiente ficou ente $33^{\circ} \mathrm{C}$ e $37^{\circ} \mathrm{C}$.

Com base no Psicrômetro de bulbo úmido e seco, foi calculada a umidade relativa e realizado a média de algumas medidas. Estes valores são decorrentes do processo de secagem do fumo na fase de amarelação.

Houve uma variação da UR na interior da estufa, como esperado, pois na estufa do caso estudado não existe nenhum controle de temperatura e nem de vazão do ar seco admitido na parte inferior da estufa bem como ar úmido na parte superior.

Todo o controle de temperatura é feito manualmente através do ar admitido pela fornalha.

Assim, se valida o uso de um sistema auxiliar como fonte de calor, como o sistema com coletores solares com armazenamento do calor em leito de pedras, já utilizado em outros trabalhos. A ideia central do uso deste sistema seria a substituição de parte da energia gerada pela queima da lenha pela energia acumulada pelo coletor solar.

\subsubsection{Consumo de lenha}

Durante o processo de cura acompanhado no estudo de caso, foi controlado o consumo de lenha, totalizando-se $5 \mathrm{~m}^{3}$ de lenha 
empilhada em madeira eucalipto no decorrer dos 6 dias. A quantidade de lenha utilizada em cada fase da cura é demonstrada na Tabela 1.

Tabela 1 - Consumo de lenha durante o processo de cura acompanhado

\begin{tabular}{l|c|c|c|c}
\hline \multicolumn{1}{c|}{ Fase } & Horas & $\begin{array}{c}\text { Lenha } \\
\text { empilhada } \\
\left(\mathbf{m}^{\mathbf{3}} \mathbf{)}\right.\end{array}$ & $\begin{array}{c}\text { Lenha } \\
\text { Volume } \\
\mathbf{s o ́ l i d o ~} \\
\left(\mathbf{m}^{3}\right)\end{array}$ & $\begin{array}{c}\text { Temperatura } \\
\left({ }^{\circ} \mathbf{C}\right)\end{array}$ \\
\hline Amarelação & 48 & 1,1 & 0,67 & 35 \\
\hline $\begin{array}{l}\text { Secagem da } \\
\text { Folha }\end{array}$ & 36 & 1,3 & 0,793 & 54 \\
\hline Secagem do talo & 60 & 2,6 & 1,586 & 71 \\
\hline TOTAL & 144 & 5,0 & 3,05 & - \\
\hline
\end{tabular}

Considerando que $1 \mathrm{~m}^{3}$ de lenha empilhada é igual a 01 estere e este igual à cerca de $0,61 \mathrm{~m}^{3}$ de volume sólido de lenha (30\% de vazios), consumiram-se $3,05 \mathrm{~m}^{3}$ de lenha em volume sólido.

Um estere de lenha de eucalipto, parcialmente seca, pesa aproximadamente 600 a $700 \mathrm{~kg}$.

2.3.4 Proposta de acoplamento do coletor solar às estufas a lenha existentes

A ideia central do uso deste sistema é que os próprios usuários pudessem construir o coletor e que parte da energia gerada pela queima da lenha fosse substituída pela energia acumulada pelo coletor solar. Assim, o sistema auxiliar de fonte de calor poderá ser acoplado às estufas à lenha existentes, de forma que 0 ar aquecido no coletor seja direcionado diretamente ao interior da estufa (Figura 11). O duto de saída do ar aquecido pelo coletor solar deve ser colocado junto à fornalha para que este circule pelos dutos de aço galvanizado, juntamente com 0 ar aquecido pela combustão da lenha, para que a umidade do ar ambiente não prejudique o processo de cura do tabaco. 


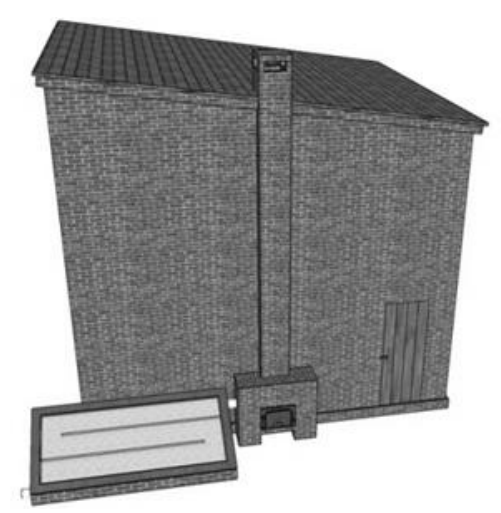

Figura 11 - Coletor solar acoplado em estufa à lenha existente.

\section{ANÁLISE DOS RESULTADOS}

\subsection{Rendimento do Sistema}

Conforme as temperaturas de entrada e de saída de ar do protótipo do coletor solar a ar composto por pedras britadas foram coletadas durante um período de 144 horas (de 15/02/2012 a $21 / 02 / 2012$ ) e que os registradores foram programados para tomar leituras a cada cinco minutos, calcularam-se as médias horárias das temperaturas de entrada e saída do coletor.

Foram ainda calculadas médias das temperaturas obtidas pelos dois equipamentos instalados na entrada do coletor e pelos três aparelhos na saída de ar deste, que totalizaram cinco registros de temperatura simultâneos, uma vez que, dois deles ainda registravam simultaneamente as temperaturas em cabos posicionados no interior do cano de PVC.

Durante o período ocorreram dois dias encobertos (dias 16/02/2012 e 18/02/2012) e três dias de céu claro (dias 17/02/2012, 19/02/2012 e 20/02/2012). Os dias 15/02/2012 e 21/02/2012 (quando as medições iniciaram e terminaram ao meio-dia) também apresentaram céu claro.

A Figura 12 ilustra o comportamento das médias horárias destas temperaturas, das quais, a linha azul representa a temperatura do ar na entrada do coletor - média de 2 sensores, e a linha vermelha representa a temperatura do ar na saída do coletor média de 3 sensores, e que cada ponto é uma média de 12 medições ao longo de uma hora. 


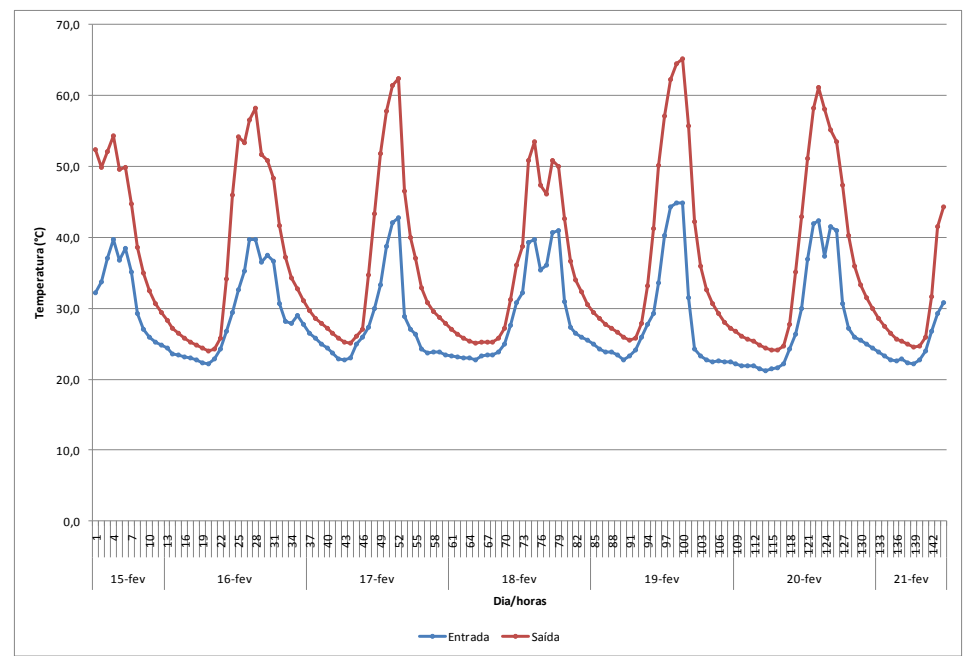

Figura 12 - Temperatura horária média do ar na entrada e na saída do coletor.

Durante o dia, a diferença de temperatura do ar entre a entrada e a saída do coletor foi bastante elevada, com valores que ultrapassam $20^{\circ} \mathrm{C}$. Durante a noite, as diferenças desses valores reduziram, mas ainda assim mostram o acúmulo de energia que ocorre no leito de brita, que continua a aquecer o ar que passa pelo coletor.

Visto que, durante, o período de medições ocorreram dois dias de céu encoberto, assumiu-se, para a análise dos dados, a média de temperaturas dos três dias mais propícios para captação de energia. Tomando-se estes valores, as curvas de medições de temperaturas apresentam os resultados na Figura 13: 


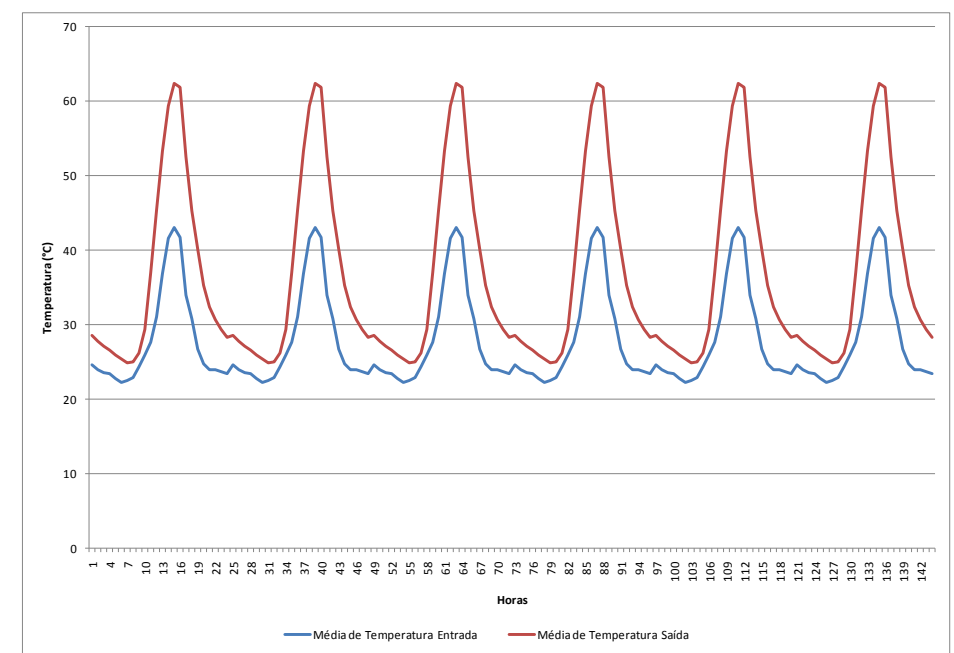

Figura 13 - Média de temperaturas de entrada e de saída do coletor dos três dias de céu claro.

3.1.1 Calor Útil $\left(Q_{u}\right)$ fornecido pelo Coletor

Para determinar o Calor Útil fornecido pelo coletor, primeiramente, calcularam-se os valores horários de entalpia $(H)$ na entrada e na saída do coletor, determinando-se a variação de entalpia do ar entre a entrada e a saída do coletor $(\Delta H)$. A taxa de Calor Útil fornecida pelo coletor foi obtida pela equação $11 \mathrm{e}$ calculada por hora.

O Quadro 01 contém alguns os dados de medições com os cálculos de Entalpia $(H)$ e Calor Útil $\left(Q_{u}\right)$ acima descritos, listados apenas como demonstração dos resultados, contendo apenas um horário dos três dias de medições (16/02/2012, 18/02/2012 e 20/02/2012), dias que representam cada fase do processo de cura (amarelação, secagem da folha e secagem do talo, respectivamente). 
Quadro 1 - Extração de três dias de medições com cálculo de entalpia e calor útil.

\begin{tabular}{|c|c|c|c|c|c|c|c|c|c|}
\hline \multirow[b]{2}{*}{ Dia } & \multirow[b]{2}{*}{$\begin{array}{l}\text { Hor } \\
\text { ário }\end{array}$} & \multirow[b]{2}{*}{$\begin{array}{c}\text { Hor } \\
\mathrm{a}\end{array}$} & \multicolumn{2}{|c|}{ Entrada } & \multicolumn{2}{|c|}{ Saída } & \multicolumn{2}{|c|}{$\begin{array}{c}\text { Entalpia (H) } \\
(\mathrm{KJ} / \mathrm{KG})\end{array}$} & \multirow{2}{*}{$\begin{array}{c}\text { Calor } \\
\text { Útil } \\
\text { (Qu) } \\
\text { forneci } \\
\text { do } \\
\text { pelo } \\
\text { Coletor } \\
-(\mathrm{KJ} / \mathrm{h})\end{array}$} \\
\hline & & & $\begin{array}{l}\text { Médi } \\
\text { a de } \\
\text { Tem } \\
\text { p. } \\
\left({ }^{\circ} \mathrm{C}\right)\end{array}$ & $\begin{array}{c}\text { Médi } \\
\text { a de } \\
\cup A \\
(\mathrm{~kg} / \mathrm{k} \\
\mathrm{g})\end{array}$ & $\begin{array}{c}\text { Médi } \\
\text { a de } \\
\text { Tem } \\
\text { p. } \\
\left({ }^{\circ} \mathrm{C}\right)\end{array}$ & $\begin{array}{c}\text { Médi } \\
\text { a de } \\
\text { UA } \\
(\mathrm{kg} / \mathrm{k} \\
\mathrm{g})\end{array}$ & Entrada & Saída & \\
\hline$(\ldots)$ & $(\ldots)$ & $(\ldots)$ & $(\ldots)$ & $(\ldots)$ & $(\ldots)$ & $(\ldots)$ & (...) & $(\ldots)$ & $(\ldots)$ \\
\hline 16 & 12 & 24 & 29,4 & $\begin{array}{c}0,013 \\
7\end{array}$ & 46,0 & $\begin{array}{c}0,024 \\
8\end{array}$ & $\begin{array}{c}347,06 \\
4\end{array}$ & $\begin{array}{c}398,25 \\
1\end{array}$ & $\begin{array}{c}10.636 \\
4\end{array}$ \\
\hline$(\ldots)$ & $(\ldots)$ & $(\ldots)$ & $(\ldots)$ & $(\ldots)$ & $(\ldots)$ & $(\ldots)$ & (...) & $(\ldots)$ & (...) \\
\hline$(\ldots)$ & $(\ldots)$ & $(\ldots)$ & $(\ldots)$ & $(\ldots)$ & $(\ldots)$ & $(\ldots)$ & (...) & (...) & $(\ldots)$ \\
\hline 18 & 12 & 72 & 30,8 & $\begin{array}{c}0,015 \\
7\end{array}$ & 36,1 & $\begin{array}{c}0,021 \\
7\end{array}$ & $\begin{array}{c}354,38 \\
1 \\
\end{array}$ & $\begin{array}{c}378,12 \\
5 \\
\end{array}$ & $4.934,0$ \\
\hline$(\ldots)$ & $(\ldots)$ & $(\ldots)$ & $(\ldots)$ & $(\ldots)$ & $(\ldots)$ & $(\ldots)$ & $(\ldots)$ & $(\ldots)$ & $(\ldots)$ \\
\hline$(\ldots)$ & $(\ldots)$ & $(\ldots)$ & $(\ldots)$ & $(\ldots)$ & $(\ldots)$ & $(\ldots)$ & $(\ldots)$ & $(\ldots)$ & $(\ldots)$ \\
\hline 20 & 12 & 120 & 29,9 & $\begin{array}{c}0,016 \\
0\end{array}$ & 42,9 & $\begin{array}{c}0,021 \\
2\end{array}$ & $\begin{array}{c}354,48 \\
0\end{array}$ & $\begin{array}{c}383,94 \\
1 \\
\end{array}$ & $6.121,7$ \\
\hline$(\ldots)$ & $(\ldots)$ & $(\ldots)$ & $(\ldots)$ & $(\ldots)$ & $(\ldots)$ & $(\ldots)$ & $(\ldots)$ & $(\ldots)$ & $(\ldots)$ \\
\hline
\end{tabular}

A Figura 14 apresenta a curva da média horária do Calor Útil $\left(Q_{u}\right)$ fornecido pelo coletor durante os seis dias de medições, que somam $922.863,5 \mathrm{KJ}$.

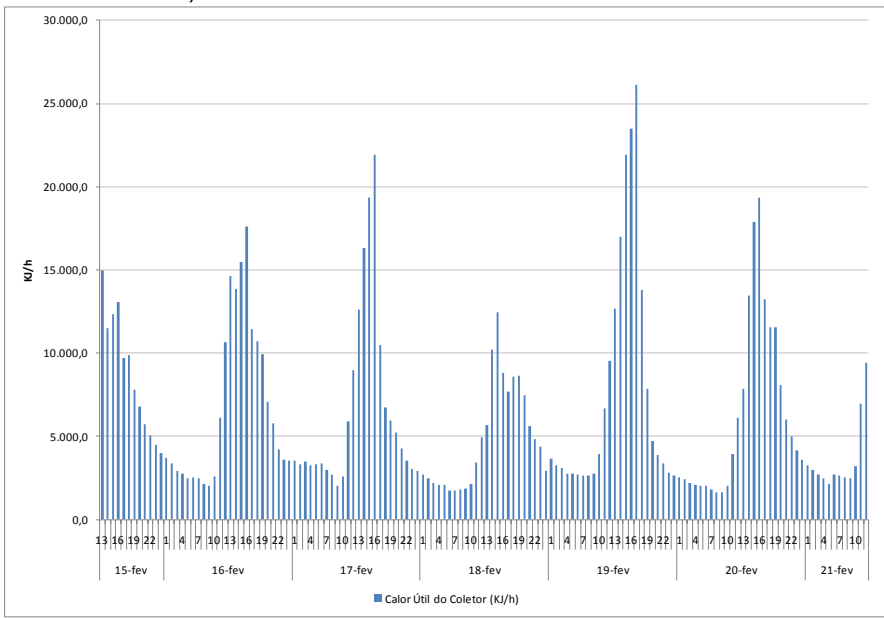

Figura 14 - Calor Útil fornecido pelo coletor. 
A Figura 15, por sua vez, apresenta o gráfico da média do Calor Útil $\left(Q_{u}\right)$ considerando um dia com valores médios dos três dias de céu claro.

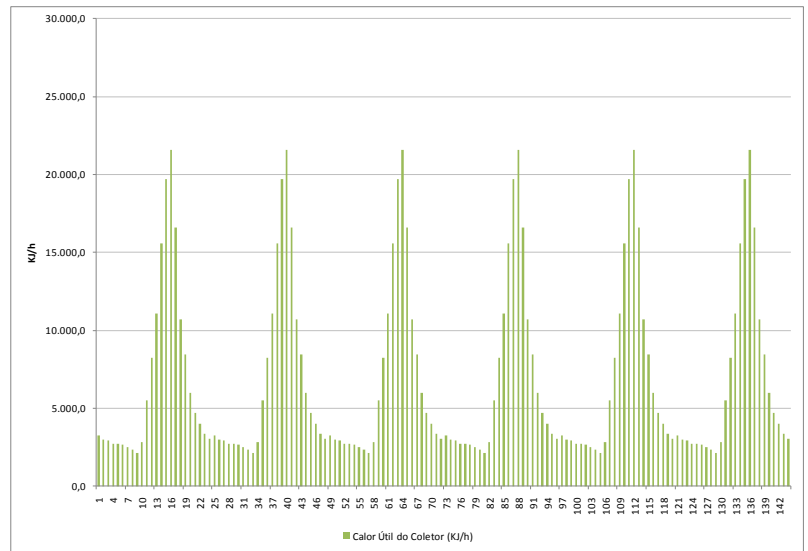

Figura 15 - Calor Útil da média dos três dias de céu claro.

\subsection{Estudo de caso - Cura do tabaco com o uso do coletor solar}

Para este estudo, foi calculada a demanda de energia e lenha que é necessária para um processo de cura com um período de seis dias e verificada a economia na demanda energética com o uso do coletor solar, considerando o Calor Útil $\left(Q_{u}\right)$ fornecido pelo coletor constatado na seção anterior. Por fim, foi determinada a viabilidade econômica de uso do coletor solar na secagem do tabaco.

\subsubsection{Demanda de energia e lenha do processo de cura}

A temperatura dentro da estufa de cura deve ser constante: $35^{\circ} \mathrm{C}$ na fase de amarelação, $54^{\circ} \mathrm{C}$ na fase de secagem da folha e $71^{\circ} \mathrm{C}$ na fase de secagem do talo. Considerando que a temperatura ambiente é variável ao longo do dia, o consumo de lenha é uma função exponencial ao longo do tempo.

Para adequar o consumo de lenha a essa variação, pressupôs-se neste estudo que o consumo de lenha seja inversamente proporcional à temperatura ambiente (quanto maior a temperatura ambiente, menor a demanda energética). Isto foi feito para cada uma das fases com base na diferença entre a temperatura 
a ser alcançada em cada fase e a temperatura medida na entrada do coletor (assumida como a temperatura ambiente). O Quadro 2 apresenta a extração de três dias de medições (16/02/2012, 18/02/2012 e 20/02/2012).

\section{Quadro 02 - Exemplo de valores para três dias de medições com cálculo de demanda e redução de lenha.}

\begin{tabular}{|c|c|c|c|c|c|c|c|}
\hline \multirow{2}{*}{ Dia } & \multirow{2}{*}{ Hora } & \multirow{2}{*}{$\begin{array}{l}\text { Temp } \\
\text { Fase } \\
\left({ }^{\circ} \mathrm{C}\right)\end{array}$} & \multirow{2}{*}{$\begin{array}{l}\text { Calor Útil (Qu) } \\
\text { fornecido } \\
\text { pelo Coletor } \\
\text { - (KJ/h) }\end{array}$} & \multicolumn{2}{|c|}{$\begin{array}{l}\text { Necessidade para } \\
\text { Cura }\end{array}$} & \multicolumn{2}{|c|}{$\begin{array}{l}\text { Redução de } \\
\text { Lenha }\end{array}$} \\
\hline & & & & $\mathrm{KJ} / \mathrm{h}$ & $\begin{array}{c}\mathrm{m}^{3} / \mathrm{h} \\
\text { Lenha }\end{array}$ & $\%$ & $\mathrm{~m}^{3}$ \\
\hline$(\ldots)$ & $(\ldots)$ & $(\ldots)$ & $(\ldots)$ & $(\ldots)$ & $(\ldots)$ & $(\ldots)$ & $(\ldots)$ \\
\hline 16 & 12 & 35 & $10.636,4$ & $56.809,2$ & 0,0114 & 18,7 & 0,0021 \\
\hline (...) & $(\ldots)$ & $(\ldots)$ & (...) & $(\ldots)$ & (...) & $(\ldots)$ & (...) \\
\hline$(\ldots)$ & $(\ldots)$ & $(\ldots)$ & $(\ldots)$ & $(\ldots)$ & $(\ldots)$ & $(\ldots)$ & $(\ldots)$ \\
\hline 18 & 12 & 54 & $4.934,0$ & $102.814,4$ & 0,0206 & 4,8 & 0,0010 \\
\hline$(\ldots)$ & (...) & $(\ldots)$ & $(\ldots)$ & $(\ldots)$ & $(\ldots)$ & $(\ldots)$ & (...) \\
\hline$(\ldots)$ & $(\ldots)$ & $(\ldots)$ & $(\ldots)$ & $(\ldots)$ & $(\ldots)$ & $(\ldots)$ & $(\ldots)$ \\
\hline 20 & 12 & 71 & $6.121,7$ & $124.480,3$ & 0,0249 & 4,9 & 0,0012 \\
\hline$(\ldots)$ & $(\ldots)$ & $(\ldots)$ & $(\ldots)$ & $(\ldots)$ & $(\ldots)$ & $(\ldots)$ & $(\ldots)$ \\
\hline
\end{tabular}

A Figura 16 apresenta a demanda de energia e consumo de lenha, calculados através do método de cálculo descrito acima, onde a maior demanda energética é no período noturno, devido à ausência da radiação solar. Nas tardes do primeiro e do segundo dias de monitoramento, a demanda energética é nula, ou seja, a temperatura ambiente superou $35^{\circ} \mathrm{C}$, a temperatura necessária para a fase de amarelação, bastando nesse caso insuflar 0 ar na temperatura ambiente. 


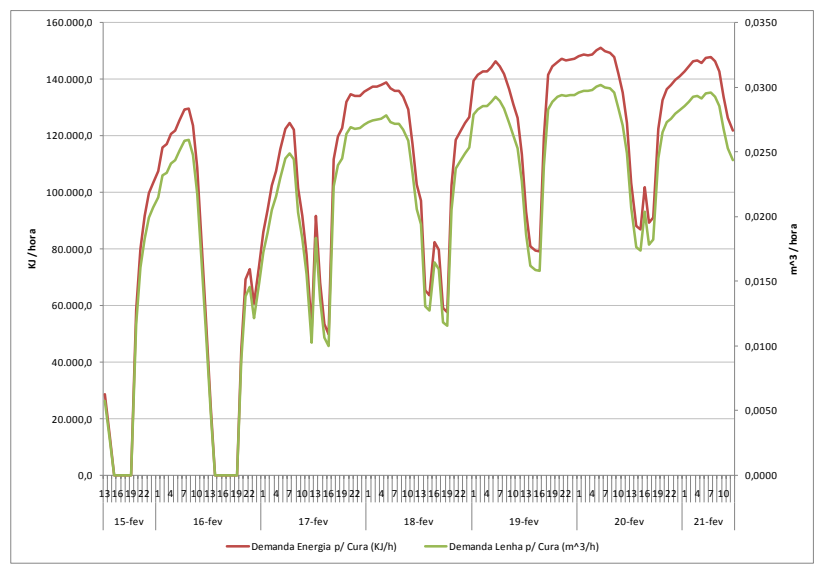

Figura 16 - Demanda de energia e consumo de lenha ao longo do período de coleta de dados.

3.2.2 Economia na demanda energética da cura do tabaco com o uso do coletor solar

Durante o processo de cura do tabaco acompanhado no estudo de caso, com duração de seis dias, foram utilizados $5 \mathrm{~m}^{3}$ de lenha empilhada, o equivalente a $3,05 \mathrm{~m}^{3}$ de lenha maciça. Considerando que o calor específico da lenha eucalipto é de $5 \mathrm{GJ} / \mathrm{m} 3$ (Bazzo, 1995), o calor necessário para um processo de cura completo é de $25.000 .000 \mathrm{KJ}$.

Analisando-se o cruzamento do Calor Útil fornecido pelo coletor e a demanda energética do processo de cura observa-se uma economia de lenha total no processo de cura é de $5,2 \%$, ou de aproximadamente $0,16 \mathrm{~m}^{3}$ de lenha (Figura 24), considerando-se puramente as medições tomadas no protótipo do coletor solar.

Considerando-se as temperaturas médias dos três dias de céu claro, a economia de lenha total no processo de cura do tabaco chega a $5,6 \%$ ou de aproximadamente $0,17 \mathrm{~m}^{3}$ de lenha.

3.2.3 Viabilidade econômica de uso do coletor solar na secagem do tabaco

A lenha foi considerada como fonte convencional de energia utilizada. O preço da lenha de eucalipto no estado do Rio Grande do Sul $\left(R \$ 53,00 / \mathrm{m}^{3}\right)$ foi obtido através da Associação dos Fumicultores do Brasil - AFUBRA (2012). 
Os materiais utilizados na construção do protótipo do coletor solar de energia com leito de pedras britadas, bem como as quantidades e preços cotados em janeiro de 2012, estão listados na Figura 17.

\begin{tabular}{|c|c|c|c|c|c|c|c|c|c|}
\hline \multicolumn{6}{|c|}{ Coletor 3X1m } & \multicolumn{4}{|c|}{ Custo estimado para: } \\
\hline Item & \begin{tabular}{|c|} 
Unidade de \\
medida \\
\end{tabular} & Qtde & R\$\$/unid. & R\$ & $\mathrm{R} \$ \mathrm{~m}^{2}$ & \begin{tabular}{|l|}
$3 \mathrm{~m} 2(3 \times 1 \mathrm{~m})$ \\
Vidro Duplo
\end{tabular} & $6 \mathrm{~m} 2(6 \times 1 \mathrm{~m})$ & $9 m 2(9 \times 1 m)$ & $12 \mathrm{~m} 2(12 \times 1 \mathrm{~m})$ \\
\hline Tijolos 6 furos padrão & milheiro & 0,17 & 380,00 & 64,60 & 21,53 & 64,60 & 129,20 & 193,80 & 258,40 \\
\hline Areia & $\mathrm{m}^{3}$ & 0,1 & 65,00 & 6,50 & 2,17 & 6,50 & 13,00 & 19,50 & 26,00 \\
\hline Cimento & saco & 0,8 & 19,90 & 15,92 & 5,31 & 15,92 & 31,84 & 47,76 & 63,68 \\
\hline Brita ${ }^{\circ} 1$ & $\mathrm{~m}^{3}$ & 1 & 60,00 & 60,00 & 20,00 & 60,00 & 120,00 & 180,00 & 240,00 \\
\hline Lona preta & $\mathrm{m}$ & 1 & 11,00 & 11,00 & 3,67 & 11,00 & 22,00 & 33,00 & 44,00 \\
\hline Madeira & ripa $3 \times 0,15$ & 3 & 1,00 & 3,00 & 1,00 & 3,00 & 6,00 & 9,00 & 12,00 \\
\hline Silicone & tubo & 1 & 12,00 & 12,00 & 4,00 & 12,00 & 24,00 & 36,00 & 48,00 \\
\hline Vidro & $\mathrm{m}^{2}$ & 3 & 57,00 & 171,00 & 57,00 & 342,00 & 342,00 & 513,00 & 684,00 \\
\hline Tubo PVC & $\mathrm{m}$ & 2 & 4,60 & 9,20 & 3,07 & 9,20 & 18,40 & 27,60 & 36,80 \\
\hline Ventilador & unidade & 1 & 208,25 & 208,25 & 208,25 & 208,25 & 208,25 & 208,25 & 208,25 \\
\hline Valor Total (R\$) & & & & 561,47 & 325,99 & 732,47 & 914,69 & $1.267,91$ & $1.621,13$ \\
\hline Valor por $\mathrm{m}^{2}$ (R\$) & & & & & 325,99 & 244,16 & 152,45 & 140,88 & 135,09 \\
\hline
\end{tabular}

Figura 17 - Custo de construção do coletor.

$\mathrm{Na}$ tabela de custos acima, o lado esquerdo apresenta os custos na montagem do protótipo (coletor com $3 \mathrm{~m}^{2}$ ). No direito, estão calculados os custos proporcionais a um coletor da mesma dimensão do protótipo com a utilização de vidro duplo e para distintas dimensões de coletores $\left(6 \mathrm{~m}^{2}, 9 \mathrm{~m}^{2}\right.$ e $\left.12 \mathrm{~m}^{2}\right)$. Nota-se a diminuição do custo $/ \mathrm{m}^{2}$ em função de alguns valores que são considerados invariáveis independentes da dimensão do coletor.

Tomando-se em conta tais custos de investimento e potenciais economias de combustível (lenha), a Figura 18 mostra que o tempo de retorno do investimento para o protótipo do coletor solar a ar composto por pedras britadas é de 3,4 anos ou três safras.

\begin{tabular}{|l|c|c|}
\hline \multicolumn{1}{|c|}{ litem } & \multirow{2}{*}{ Unidade } & Protótipo \\
\cline { 3 - 3 } & & $\mathbf{3 ~ m}^{\mathbf{2}}$ \\
\hline Volume Lenha por processo & $\mathrm{m}^{3}$ & 5 \\
\hline Valor da lenha & $\mathrm{R} \$ \mathrm{~m}^{3}$ & 53,00 \\
\hline Quantidade processos por safra & un. & 12 \\
\hline Economia de lenha & $\%$ & $5,2 \%$ \\
\hline Investimento em estrutura & $\mathrm{R} \$$ & 561,47 \\
\hline Consumo normal lenha & $\mathrm{m}^{3}$ & 60,0 \\
\hline Consumo normal lenha & $\mathrm{R} \$$ & $3.180,00$ \\
\hline Redução consumo lenha & $\mathrm{m}^{3}$ & 3,1 \\
\hline Redução consumo lenha & $\mathrm{R} \$$ & 164,98 \\
\hline Tempo retorno investimento & safra & $\mathbf{3 , 4}$ \\
\hline
\end{tabular}

Figura 18 - Retorno de investimento para o protótipo de $3 \mathrm{~m}^{2}$. 
Para os estudos de viabilidade econômica de coletores com utilização de vidro duplo ou com diferentes dimensionamentos, seriam necessários novos levantamentos de dados, já que dobrar o tamanho do coletor não necessariamente dobraria o calor útil fornecido por este e que as perdas também não seriam as mesmas.

Conforme a Tabela 1, o coletor solar a ar composto por pedras britadas de $3 \mathrm{~m}^{2}$ com utilização de vidro duplo é o modelo sugerido com menor custo $/ \mathrm{m}^{2}$, sendo que neste caso o isolamento da caixa é de extrema importância para que a eficiência deste seja superior ao protótipo deste estudo.

\section{CONCLUSÃO}

Neste trabalho foi projetado, construído e avaliado um coletor solar com leito de pedras britadas para pré-aquecimento de ar com materiais de baixo custo e de fácil execução, que pode ser utilizado de maneira a subtrair custos nos processos de secagem. Além da contribuição ao meio ambiente com redução da eliminação de gases tóxicos.

O protótipo do coletor, construído na cidade de Santa Cruz do Sul - RS, com uma área de $3 \mathrm{~m}^{2}$, demonstrou ser de fácil execução, de forma que o próprio agricultor poderia fazê-la. Além do custo benefício da utilização de materiais de baixo custo e retorno do investimento em 3, 4 anos.

O dimensionamento do coletor e a utilização de vidro duplo são sugestões para pesquisas futuras, assim como o estudo de caso de aplicação desse coletor para secagem de outras culturas agrícolas.

\section{REFERÊNCIAS BIBLIOGRÁFICAS}

ALMEIDA, D. Psicrometria: apontamentos de apoio as aulas de tecnologia pós-colheita, Faculdade de Ciências, Universidade do Porto, 2004 Disponível em: $<$ http://dalmeida.com/poscolheita/ISA2005/Psicrometria-Almeida2004.pdf>. Acesso em 05 mar. 2012.

ASHRAE Standard 93: Methods of testing to determine the thermal performance of solar collectors, American society of heatihg, refrigeration and air conditioning engineers, Nova lorque, 2010.

AFUBRA. ASSOCIAÇÃO DOS FUMICULTORES DO BRASIL. Disponível em: <http://www.afubra.com.br/>. Acesso em: 11 jan. 2012. 
BAZZO, E. Geração de vapor, 2. ed., Florianópolis: Ed. da UFSC, 1995. 216p.

GRATTO, D. A.; SANTINI, E. J.; HASELEIN, C. R.; DURLO, L. A. Características da lenha produzida na região da quarta colônia de imigração italiana do Rio Grande do Sul. Ciência Florestal, vol. 13, número 002. Universidade Federal de Santa Maria, Santa Maria, Brasil, 2003.

GUANDAGNIN, O. Secagem de grãos com energia solar: experiência realizada na propriedade do senhor Adilson Peruzzo. Nova Bassano: Emater, 2005. Disponível em: $<\mathrm{http}: / /$ www.emater.tche.br/site/br/arquivos/area/frentes/1/secagem graos.pdf>. Acesso em 17 out. 2009.

SANTOS, B. M. Metodologia de dimensionamento de sistemas de aquecimento solar para secagem de produtos agrícolas. $78 p$. Dissertação (Mestrado em Engenharia Agrícola) - Faculdade de Engenharia Agrícola - Universidade Estadual de Campinas, 2004. Disponível em:

http://www.bibliotecadigital.unicamp.br/document/?code=vtls0003622 29>. Acesso em 02 set. 2011. 